Document downloaded from:

http://hdl.handle.net/10251/70147

This paper must be cited as:

Elena Fito, SF.; Bernet, GP.; Carrasco Jiménez, JL. (2014). The games plant viruses play. Current Opinion in Virology. 8:62-67. doi:10.1016/j.coviro.2014.07.003

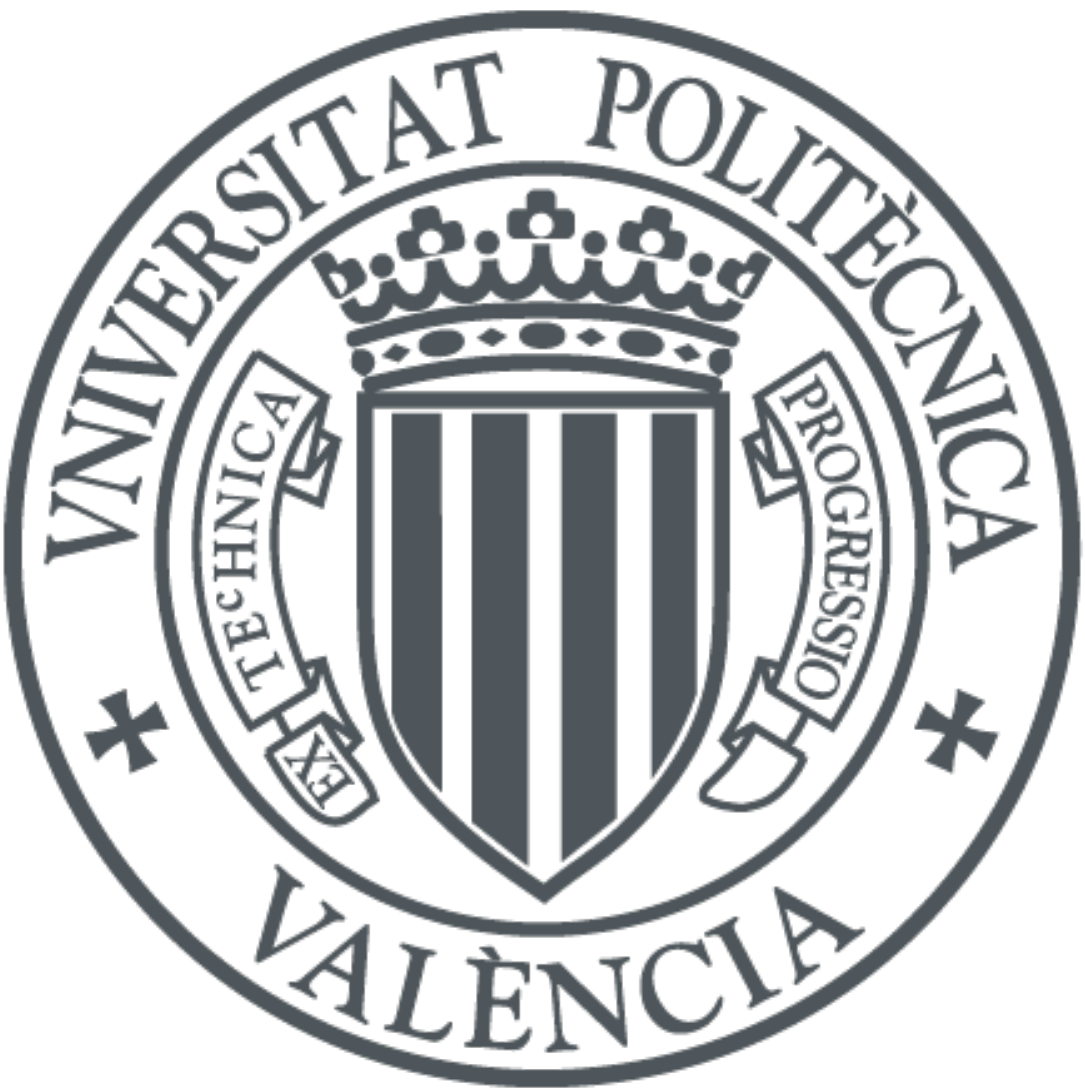

The final publication is available at

http://dx.doi.org/10.1016/j.coviro.2014.07.003

Copyright Elsevier

Additional Information 


\section{The games plant viruses play}

Santiago F. Elena ${ }^{1,2}$, Guillermo P. Bernet ${ }^{1}$, José L. Carrasco ${ }^{1}$

${ }^{1}$ Instituto de Biología Molecular y Celular de Plantas (CSIC-UPV), Campus UPV CPI

$8 \mathrm{E}$, Ingeniero Fausto Elio s/n, 46022 València, Spain

${ }^{2}$ The Santa Fe Institute, 1399 Hyde Park Road, Santa Fe, NM 87501, USA

Corresponding author: Santiago F. Elena. E-mail: santiago.elena@csic.es. Phone: +34 963877895 . 
Mixed virus infections in plants are common in nature. The outcome of such virusvirus interactions ranges from cooperation and coexistence (synergism) to mutual exclusion (antagonism). A priori, the outcome of mixed infections is hard to predict. To date, the analyses of plant virus mixed infections were limited to reports of emerging symptoms and/or to qualitative, at best quantitative, descriptions of the accumulation of both viruses. Here, we show that evolutionary game theory provides an adequate theoretical framework to analyze mixed viral infections and to predict the long-term evolution of the mixed populations.

\section{Highlihgts:}

- The outcome of mixed virus plant infections is complex and hard to predict

- Game theory provides tools to study interactions between viruses

- Mutual cooperation is the most commonly game played by plant viruses

- Molecular biology of viruses may explain how certain games are played

\section{Introduction}

An interesting phenomenon of plant viral disease, which is not so common among animal viruses, is synergism during coinfection $\left[1^{* *}\right]$. Coinfection by two distinct viruses or by two strains of the same virus results in complex interactions with unpredictable disease phenotypes $\left[1^{* *}\right]$. In general, antagonistic interactions lead to mutual exclusion and, eventually, to cross-protection. By contrast, synergism enhances fitness components of at least one of the members of the viral complex and the effect on the host becomes greater than the sum of the individual effects. Mixed infections can also modify viral traits such as host range [2-5], transmission rate [6,7], cellular tropism $[8,9]$, titer $\left[3,10^{*}, 11\right]$, and even the biology and preference of vectors [12]. Umbraviruses and their luteovirus helpers provide particularly suggestive examples of synergism, illustrating the degree of dependence that can be achieved among pairs of viruses. Umbraviruses such as Groundnut rosette virus (GRV) do not encode for a coat protein and use the capsids of its luteovirus helper Groundnut rosette assistor virus (GRAV) for aphid transmission [13]. In this particular case, the situation is even more 
complex since encapsidation of GRV in the GRAV capsid proteins requires of the intervention of a GRV satellite RNA that co-encapsidates [13].

In mixed infections, each viral population changes the environment and becomes part of the fitness landscape of the co-infecting virus population. Therefore, in mixed infections the success of any virus depends not only on its adaptation to the host, but also on how its behavior interacts with that of others. So the fitness of an individual virus cannot be measured in isolation; rather it has to be evaluated in the context of the community in which it lives. This opens the door to a natural game-theoretic analogy: genetically-determined characteristics and behaviors of a virus are like its strategy in a game, its fitness is like its payoff, and this payoff depends on the strategies of the viruses with which it interacts. Biological games can be conveniently modeled and analyzed using the mathematical framework provided by game theory $\left[14,15^{* *}\right]$. The players have to choose between strategies whose payoff depends on their rivals' strategies $\left[15^{* *}, 16\right]$. Cooperation and defection are the two strategies that are usually at the heart of every social dilemma. While cooperative individuals contribute to the collective welfare at a cost, defectors choose not to [15 $\left.{ }^{* *}-17\right]$.

\section{The payoff matrix}

In the simplest situation, two players can chose between two strategies, cooperation or defection. Viral cooperation and defection can be defined as, respectively, the manufacturing and sequestering of diffusible (shared) intracellular products (Figure 1). The $2 \times 2$ payoff matrix shown in Table 1 is the fundamental tool to analyze and predict the outcome of the contest. Each player has a different fitness depending on the frequency of competitors in the population. The entries denote the payoff for the row player. If player A decides to cooperate, its fitness would depend on player B's response. If $\mathrm{B}$ cooperates, then both players receive a fitness reward $R$ for their mutual cooperation. However, if B decides to defect, A suffers a reduction in fitness $S$ (the sucker's payoff). Lets turn now to the situation in which A decides to defect. If B still cooperates, then A gets an additional fitness bonus $T$ (the temptation of defect). Finally, if both players decide to defect, they both suffer a fitness punishment $P$.

In a well-mixed population (i.e., no spatial structure exists in the system and thus all encounters are equally likely to happen), there are four possible outcomes, depending 
on the relative values of the four elements of the payoff matrix [16,17]. (i) If $R>T$ and $S>P$, then no conflict exists and mutual cooperation (MC) is the dominant strategy. Indeed, this solution provides a single stable equilibrium in which both populations coexist. (ii) If parameters satisfy the condition $R<T$ and $S<P$, then mutual defection is the dominant strategy, which also corresponds to a stable equilibrium in which, in the long term, only one of the populations persists. This game corresponds to the famous Prisoner's Dilemma (PD). (iii) If $R>T$ and $S<P$, then both contenders will benefit when acquiring the same strategy (mutual cooperation or mutual defection), but will suffer punishment when choosing a strategy different from that of their counterpart. This game is known as the Stag-Hunt ( $\mathrm{SH}$ ) and gives rise to two symmetric non-stable equilibria, thus representing a potential problem as populations may get trapped in the suboptimal mutual defection equilibrium. Finally, (iv) if parameter values are such that $R<T$ and $S>P$, we are in the domain of the Hawk-Dove game (HD). In this game cooperation is better only when the other player defects and vice versa, defection is better when the opponent cooperates. The stable equilibrium for this game is to adopt a strategy different from that of the other player.

Last, another concept to keep in mind is that of an evolutionary stable strategy (ESS). Maynard Smith [19] defined a population as evolutionary stable if it is resistant to invasion by a small group of individuals playing a different game. Put in other words: if a virus were genetically determined to cooperate, would it persist in the presence of another virus that is defecting? The mathematical conditions for ESS are that $R>T$ or that $R=T$ and $S>P$. Thus cooperation is an ESS in MC and SH games.

\section{Common games among plant viruses}

Available data are scarce to properly address whether plant viruses may prefer one strategy to another. Yet, Table 2 shows the results from the analyses of payoff matrices constructed for a set of 25 viruses, from 10 genera (including both DNA and RNA genomes), in 18 pairwise combinations. Regardless the nature of the viruses involved

in the pair, MC is the most commonly played game. This game represents the case of perfect synergism in which both competitors benefit from each other. Since MC is an ESS, two viruses involved in this game will coexist in the infected plant for long periods of time. The second most commonly played game is HD. According to this game, both viruses compete for a limiting resource. If one competitor is better using a 
given resource than the other, then it gets full benefit; but if both competitors are equally fit, they negatively affect each other. Intuitively, a hawk will do very well in a population of doves - but in a population of all hawks, a dove will actually do better by staying out of the way while the hawks fight with each other. HD is not an ESS, meaning that two viruses cannot persist together for long, as one will ultimately outcompete the other.

Table 2 suggests some other interesting things that need to be explored in the future. First, the game chosen by a pair of viruses may depend on the host. Indeed, ZYMV and CMV play $\mathrm{MC}$ in most cases but switch to $\mathrm{SH}$ in a particular host. Second, the developmental stage of the plant may also influence the game played. In young leaves, where cell division takes place and photoassimilates are being imported, competition between SPFMV and SPCSV is strong for infecting the new cells and the interaction is ruled by an $\mathrm{SH}$ game. By contrast, in mature leaves, where cell division is not so important and photoassimilates are being actively exported, promoting systemic virus movement out of the leaf, these two viruses are playing MC. Finally, given a viral genus, the probability of choosing a particular strategy varies depending on the competitor. For instance, potyviruses show significant heterogeneity in their responses $\left(\chi^{2}=20.250,6\right.$ d.f., $\left.P<0.001\right)$ : MC is the most common against cucumoviruses but HD is the most common against criniviruses.

\section{Games are grounded in molecular interactions}

One of the best-studied mechanisms of synergism is via the blockage of the RNA silencing antiviral response by viral suppressors of RNA silencing (VSR) [34-37** (Figure 1). For example, potyvirus SPFMV and crinivirus SPCSV are mostly involved in HD games, which is not ESS (Table 1). It has been long established that potyviruses may enhance other viruses' replication due to their VSR HC-Pro. HC-Pro is a cytoplasmic protein that prevents the assembly of siRNAs into the active RISC by binding to and sequestering duplex siRNAs [38]. However, SPCSV does not need to use HC-Pro since it encodes for a dsRNA-specific class 1 RNA endoribonuclease III (RNase3) that suppresses RNAi in an endonuclease activity-dependent manner [39]. RNase 3 cleaves siRNAs to products of $14 \mathrm{bp}$ that are inactive in RNAi. Therefore, both viruses compete in equal conditions to exploit the cell until one displaces the other. It is impossible to predict who the winner will be. A different example is coinfection 
between potyviruses and the cucumovirus CMV [25,40, 41]. In general, potyviruses and CMV are involved in a MC game, which is an ESS (Table 1). CMV VSR 2b accumulates in the nucleus and cytoplasm of plant cells and inhibits intercellular silencing spread and may also play a role in enhancing translation by suppressing translational repression caused by siRNAs. Therefore, cooperation may arise from HCPro assisting in CMV replication at the single-cell level whereas $2 \mathrm{~b}$ may facilitate systemic movement of potyviruses by blocking the spread of potyvirus-specific siRNAs. In this situation, both viruses can coexist indefinitely.

Synergism does not always depend on the suppression of RNA silencing. Other mechanisms exist. For example, begomovirus protein $\mathrm{C} 2$ expression reactivates cell cycle, thus promoting the replication of other coinfecting begomovirus but not of RNA viruses [9]. As an additional example, the potyvirus movement protein P3N-PIPO facilitates the systemic spread of the potexvirus White clover mosaic virus without enhancing virus accumulation per cell [42] (Figure 1). In some instances, synergism may result for more complex reasons than the action of a few viral proteins. For example, coinfection of Nicotiana benthamiana by PVY and the potexvirus Potato virus $X$ results in aggravation of symptoms as a consequence of the altered expression of many genes that were not altered by any of the single infections [43]. These genes were scattered among several metabolic pathways, confirming that host response to virus synergism includes a coordinated rearrangement of a wide array of cellular processes rather than a simple induction of genes involved in stress response.

\section{Conclusions}

Simple viruses exhibit surprisingly complex behaviors during competition. In each case, evolutionary game theory sheds light on the exact mechanism by which interaction takes place. From an academic perspective, more systematic data will allow to explore the reproducibility of the games, to analyze whether certain viral genera have a tendency to play a given game, and to explore the influence of host species, of other environmental factor, and of plant developmental stages on the games played by viral contenders. Experiments must be designed keeping in mind the sort of information needed to construct payoff matrices. And a further step will be to analyze multi-player $(>2)$ games. 
From a more practical perspective, evolutionary game theory may contribute to better understand the foundations of cross-protection. Cross-protection describes the phenomenon by which infection with a mild strain protects against subsequent infection from a severe one of a closely related virus [1,44]. Genetically modified plants do not perform as well as expected against viral infections. Therefore, the usage of coinfecting viruses to cross-protect seems a reasonable strategy worth exploring.

\section{Acknowledgements}

This work was supported by the Spanish Secretaría de Estado de Investigación, Desarrollo e Innovación grant BFU2012-30805.

\section{References and recommended reading}

Papers of particular interest, published within the period of review, have been highlighted as:
* of special interest
** of outstanding interest

1. Syller J: Facilitative and antagonistic interactions between plant viruses in mixed infections. Molecular Plant Pathology 2012, 13:204-216.

** Excellent and updated review on mixed plant virus infections, with a good number of very nice examples. It also discusses the concept of cross-protection.

2. Hacker DL, Fowler $\mathrm{BC}$ : Complementation of the host range restriction of Southern cowpea mosaic virus in bean by Southern bean mosaic virus. Virology 2000, 226:140-149.

3. Wang Y, Lee KC, Gaba V, Wong SM, Palukaitis P, Gal-On A: Breakage of resistance to Cucumber mosaic virus by co-infection with Zucchini yellow mosaic virus: enhancement of CMV accumulation independent of symptom expression. Archives of Virology 2004, 149:379-396.

4. García-Cano E, Resende RO, Fernández-Muñoz R, Moriones E: Synergistic interaction between Tomato chlorosis virus and Tomato spotted wilt virus results in breakdown of resistance in tomato. Phytopathology 2006, 96:12631269. 
5. Martínez F, Elena SF, Daròs JA: Fate of artificial microRNA-mediated resistance to plant viruses in mixed infections. Phytopathology 2013, 103:870876.

6. Hibino H: Transmission of two rice tungro-associated viruses and Rice waika virus from doubly or singly infected source plants by leafhopper vectors. Plant Disease 1983, 67:774-777.

7. Wintermantel WM, Cortez AA, Anchieta AG, Gulati-Sakhuja A, Hladky LL: Coinfection by two criniviruses alters accumulation of each virus in a hostspecific manner and influences efficiency of virus transmission. Phytopathology 2008, 98:1340-1345.

8. Wege C, Siegmund D: Synergism of a DNA and a RNA virus: enhanced tissue infiltration of the begomovirus Abutilion mosaic virus (AbMV) mediated by Cucumber mosaic virus (CMV). Virology 2007, 357:10-28.

9. Caracuel Z. Lozano-Durán R, Huguet S, Arroyo-Mateos M, Rodríguez-Negrete EA, Bejarano ER: C2 from Beet curly top virus promotes a cell environment suitable for effective replication of geminiviruses, providing a novel mechanism of viral synergism. New Phytologist 2012, 194:846-858.

10. Martín S, Elena SF: Application of game theory to the interaction between plant viruses during mixed infections. Journal of General Virology 2009, 90:2815-2820.

* First application of game theory to the analysis of plant virus mixed infections.

11. Chen Z, Tan JY, Wen Y, Niu S, Wong SM: A game-theoretic model of interactions between Hibiscus latent Singapore virus and Tobacco mosaic virus. PLoS ONE 2012, 7:e37007.

12. Srinivasan R, Álvarez JM: Effect of mixed viral infections (Potato virus Y-Potato leafroll virus) on biology and preference of vectors Myzus persicae and Macrosiphum euphorbiae (Hemiptera: Aphididae). Journal of Economic Entomology 2007, 100:646-655.

13. Syller J: Molecular and biological features of umbraviruses, the unusual plant viruses lacking genetic information for a capsid protein. Physiology and Molecular Plant Pathology 2003, 63:35-46.

14. Nowak MA, Sigmund K: Evolutionary dynamics of biological games. Science 2004, 303:793-799. 
15. Nowak MA: Five rules for the evolution of cooperation. Science 2006, 314:15601563.

${ }^{* *}$ A must-be-read primer on game theory for biologists.

16. Taylor C, Nowak MA: Transforming the dilemma. Evolution 2007, 61:22812292.

17. Archetti M, Scheuring I: Review: Game theory of public goods in one-shot social dilemmas without assortment. Journal of Theoretical Biology 2012, 299:9-20.

18. Perc M, Szolnoki A: Coevolutionary games - a mini review. Biosystems 2010, 99:109-125.

19. Maynard Smith J: The theory of games and the evolution of animal conflicts. Journal of Theoretical Biology 1974, 47:209-221.

20. Alves-Júnior M, Alfenas-Zerbini P, Andrade EC, Esposito DA, Silva FN, da Cruz ACF, Ventrella MC, Otoni WC, Zerbini FM: Synergism and negative interference during co-infection of tomato and Nicotiana benthamiana with two bipartite begomoviruses. Virology 2009, 387:257-266.

21. Fattouh FA: Double infection of a cucurbit host by Zucchini yellow mosaic virus and Cucumber mosaic virus. Pakistan Journal of Plant Pathology 2003, 2:85-90.

22. Kanakala S, Jythsna P, Shukla R, Tiwari N, Veer BS, Swarnalatha P, Krishnareddy M, Malathi VG: Asymmetric synergism and heteroencapsidation between two bipartite begomoviruses, Tomato leaf curl New Delhi virus and Tomato leaf curl Palampur virus. Virus Research 2013, 174:126-136.

23. Karyeija RF, Kreuze JF, Gibson RW, Valkonen JPT: Synergistic interactions of a potyvirus and a phloem-limited crinivirus in sweet potato plants. Virology 2000, 269:26-36.

24. Kokkinos CD, Clark CA: Interactions among Sweet potato chlorotic stunt virus and different potyviruses and potyvirus strains infecting sweetpotato in the United States. Plant Disease 2006, 90:1347-1352.

25. Mascia T, Cillo F, Fanelli V, Finetti-Sialer MM, De Stradis A, Palukaitis P, Gallitelli D: Characterization of the interaction between Cucumber mosaic virus and Potato virus $\boldsymbol{Y}$ in mixed infections in tomato. Molecular Plant-Microbe Interaction 2010, 23:1514-1524.

26. Murphy JF, Bowen KL: Synergistic disease in pepper caused by the mixed infection of Cucumber mosaic virus and Pepper mottle virus. Phytopathology 2006, 96:240-247. 
27. Pohl D, Wege C: Synergistic pathogenicity of a phloem-limited begomovirus and tobamoviruses, despite negative interference. Journal of General Virology 2007, 88:1034-1040.

28. Rentería-Canett I, Xoconostle-Cázares B, Ruiz-Medrano R, Rivera-Bustamante RF: Geminivirus mixed infection on pepper plants: synergistic interaction between PHYVV and PepGMV. Virology Journal 2011, 8:104.

29. Scheets K: Maize chlorotic mottle machlovirus and wheat streak mosaic rymovirus concentrations increase in the synergistic disease corn lethal necrosis. Virology 1998, 242:28-38.

30. Takeshita M, Koizumi E, Noguchi M, Sueda K, Shimura H, Ishikawa N, Matsuura $\mathrm{H}$, Ohsima $\mathrm{K}$, Natsuaki $\mathrm{T}$, Kuwata $\mathrm{S}$, et al.: Infection dynamics in viral spread and interference under the synergism between Cucumber mosaic virus and Turnip mosaic virus. Molecular Plant-Microbe Interaction 2012, 25:18-27.

31. Tatineni S, Graybosch RA, Hein GL, Wegulo SN, French R: Wheat cultivarspecific disease synergism and alteration of virus accumulation during coinfection with Wheat streak mosaic virus and Triticum mosaic virus. Phytopathology 2010, 100:230-238.

32. Wang Y, Gaba V, Yang J, Palukaitis P, Gal-On A: Characterization of synergy between Cucumber mosaic virus and potyviruses in cucurbit hosts. Phytopathology 2002, 92:51-58.

33. Zheng R, Liao Q, Feng J, Li D, Chen J: Synergy between Cucumber mosaic virus and Zucchini yellow mosaic virus on Cucurbitaceae hosts tested by real-time reverse transcription-polymerase chain reaction. Acta Biochimica et Biophysica Sinica 2007, 39:431-437.

34. Savenkov EI, Valkonen JP: Potyviral helper-component proteinase expressed in transgenic plants enhances titers of Potato leaf roll virus but does not alleviate its phloem limitation. Virology 2001, 283:285-293.

35. González-Jara P, Atencio FA, Martínez-García B, Barajas D, Tenllado F, DíazRuíz JR: A single amino acid mutation in the Plum pox virus helper component-proteinase gene abolishes both synergistic and RNA silencing suppression activities. Phytopathology 2005, 95:894-901.

36. Fukuzawa N, Itchoda N, Ishihara T, Goto K, Masuta C, Matsumura T: HC-Pro, a potyvirus RNA silencing suppressor, cancels cycling of Cucumber mosaic virus in Nicotiana benthamiana plants. Virus Genes 2010, 40:440-446. 
37. Pruss G, Ge X, Shi XM, Carrington JC, Bowman Vance V: Plant viral synergism: the potyviral genome encodes a broad-range pathogenicity enhancer that transactivates replication of heterologous viruses. Plant Cell 1997, 9:859-868.

${ }^{* *}$ One of the earliest evidences showing the synergism results from suppression of RNA silencing activity.

38. Lakatos L, Csorba T, Pantaleo V, Chapman EJ, Carrington JC, Liu YP, Dolja VV, Calvino LF, López-Moya JJ, Burgyán J: Small RNA binding is a common strategy to suppress RNA silencing by several viral suppressors. $E M B O$ Journal 2006, 25:2768-2780.

39. Cuellar WJ, Kreuze JF, Rajamäki ML, Cruzado KR, Untiveros M, Valkonen JP: Elimination of antiviral defense by viral RNase III. Proceedings of the National Academy of the United States 2009, 106:10354-10358.

40. Mitter N, Sulistyowati E, Dietzgen RG: Cucumber mosaic virus infection transiently breaks dsRNA-induced transgenic immunity to Potato virus $Y$ in tobacco. Molecular Plant-Microbe Interaction 2003, 16:936-944.

41. Ryang BS, Kobori T, Matsumoto T, Kosaka Y, Ohki ST: Cucumber mosaic virus 2b protein compensates for restricted systemic spread of Potato virus $Y$ in doubly infected tobacco. Journal of General Virology 2004, 85:3405-3414.

42. Hisa Y, Suzuki H, Atsumi G, Choi SH, Nakahara KS, Uyeda I: P3N-PIPO of Clover yellow vein virus exacerbates symptoms in pea infected with White clover mosaic virus and is implicated in viral synergism. Virology 2013, 244:200-206.

43. García-Marcos A, Pacheco R, Martiáñez J, González-Jara P, Díaz-Ruíz JR, Tenllado F: Transcriptional changes and oxidative stress associated with the synergistic interaction between Potato virus $X$ and Potato virus $Y$ and their relationship with symptom expression. Molecular Plant-Microbe Interactions 2009, 22:1431-1444.

44. Valle RP, Skrzeczkowski J, Morch MD, Joshi RL, Gargouri R, Drugeon G, Boyer JC, Chapeville F, Haenni AL: Plant viruses and new perspectives in crossprotection. Biochimie 1988, 70:695-703. 
Table 1

The payoff matrix for the interaction between two players

Type of adversary (B)

\begin{tabular}{lrcc}
\cline { 3 - 3 } Player who wins the payoff (A) & Cooperator & Defector \\
\cline { 3 - 4 } & Cooperator & $R$ & $S$ \\
& Defector & $T$ & $P$ \\
\hline
\end{tabular}

The standard scaled parameterization entails designing $R=1$ and $P=0$ as fixed [18]. 


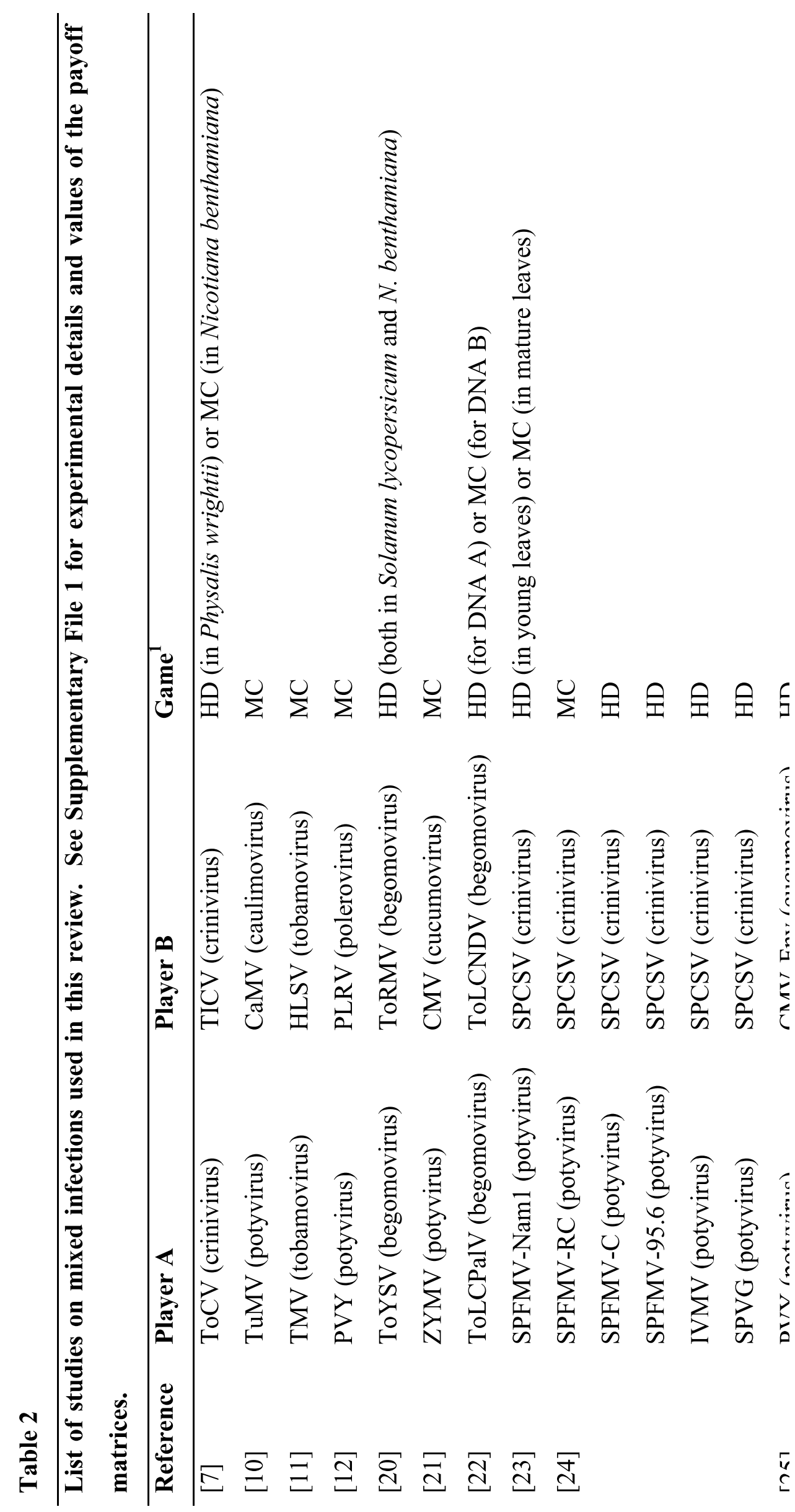




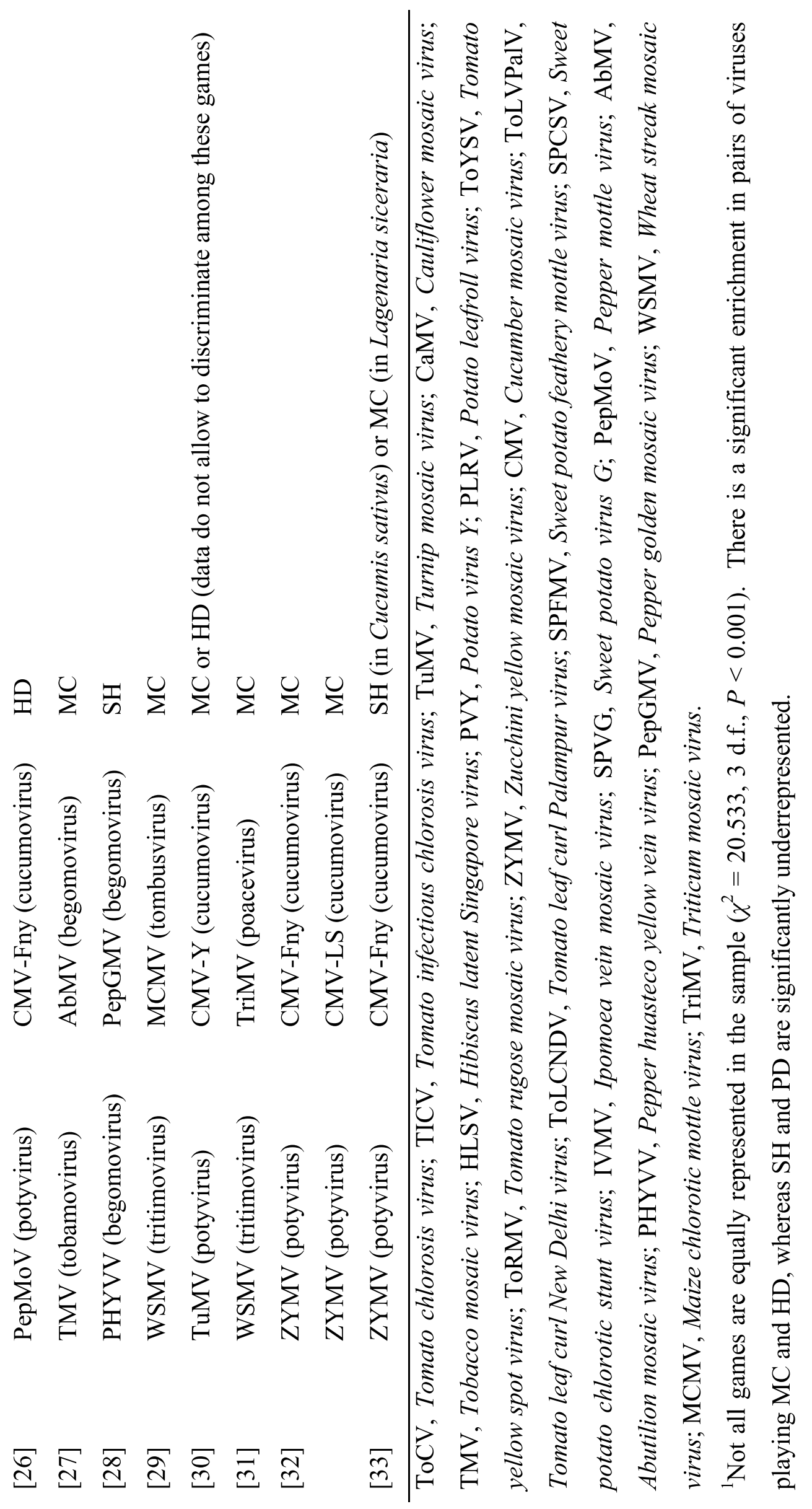


Figure 1. Molecular pathways in which a virus (in red) may impact the infec of a second co-infecting virus (in blue). Mesophyll cells are depicted in $\xi$ phloem tissue in brown. Viruses are represented by their genome and the cap uncoating, virus replicates and accumulates within the cell, forming new vira that may move from cell to cell via plasmodesmata until being loaded into $t$ for systemic long-distance movement. The major processes that may be aff consequence of viral synergism are indicated with numbers: 1, viral replicatio silencing; 3, virus movement, either cell-to-cell or long-distance through the 1 host gene expression; 5, virus transmission by vectors. VF refers to vis mediating the synergistic effect: VSR, viral suppressor of RNA silenc movement protein; $\mathrm{CP}$, coat protein. Components of the plant RNA machinery are also shown: DICER, endonuclease responsible for genera1 interfering RNAs (siRNAs) from dsRNA; siRNAs are recognized by argonau (AGO) and incorporated into the RNA-induced silencing complex (RISC), I eventually target the complementary RNA sequence. A virus may accumulation of another co-existing virus by directly or indirectly altering its 1 rate (1), or interfering with inhibitory plant RNA silencing mechanisms by ' suppressor activity (2). It may also complement deficient short- or lon movement of the accompanying virus, (3), differentially modify host gene r (4), or facilitate horizontal transmission by vectors, e.g. by heteroencapsic While mostly cooperative, and shown here as independent for the $\mathrm{p}$ simplification, these interactions may be antagonistic in some cases and may interconnected. 


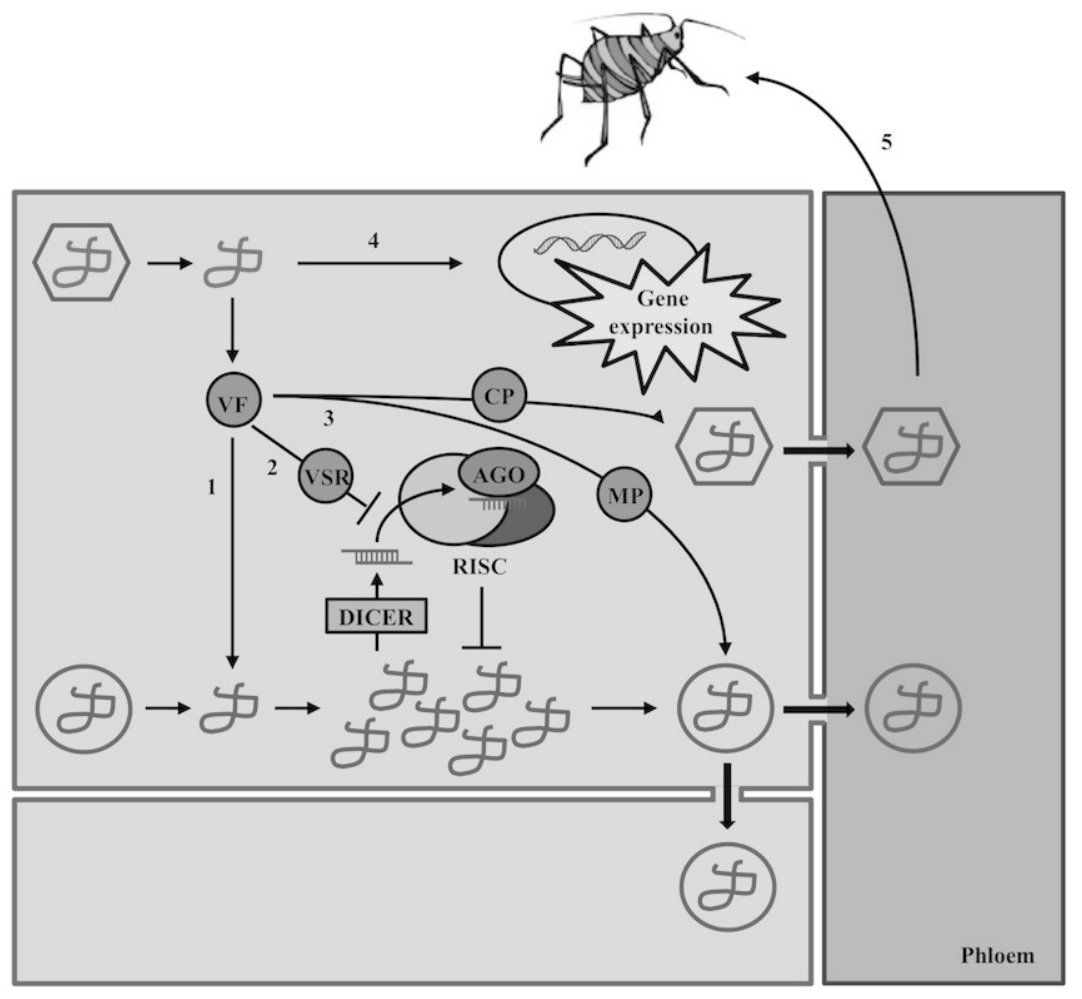

